\title{
STUDIES OF ALKALOSIS. I. RENAL FUNCTION DURING AND FOLLOWING ALKALOSIS RESULTING FROM PYLORIC OBSTRUCTION ${ }^{1}$
}

\author{
BY CHARLES H. BURNETT, BELTON A. BURROWS, 2 AND ROBERT R. COMMONS 3 \\ (From the Evans Memorial, Massachusetts Memorial Hospitals, and the Department of Medicine, \\ Boston University School of Medicine, Boston)
}

(Received for publication July 14, 1949)

\section{INTRODUCTION}

The combination of alkalosis and renal insufficiency has been reported repeatedly (1-15). The causes of the failure of kidney function, and the nature of the renal lesion have not been defined clearly. The evidence suggests that normal kidneys may suffer considerable functional impairment as a result of alkalosis, and subsequently undergo complete restitution. To the authors' knowledge normal renal function has never been demonstrated in any patient prior to the observation of persistently reduced kidney function after alkalosis. This report describes renal function measurements in five patients who had alkalosis resulting primarily from loss of gastric contents and varying degrees of renal impairment. The data indicate in each instance that there was a partially to completely reversible type of renal failure with certain common characteristics. As with other reports, in no instance where renal function has not returned to normal can it positively be stated that the kidneys were normal prior to the time of first observation when renal failure was already present.

\section{METHODS AND MATERIAL}

Five patients were studied during the acute phases of alkalosis and at varying intervals thereafter. Chemical methods employed in analysis of the blood and urine, exclusive of those employed in estimating the renal function, are described in another report (16). Clearance of inulin, mannitol and para-aminohippuric acid, and maximal tubular excretory capacity of para-aminohippuric acid were determined essentially according to Goldring and Chasis (17). Urine was collected with indwelling catheters, and the bladder was rinsed with isotonic saline or

1 Part of this work was done under contract with the Army Medical Research and Development Board, and during the tenure of a Life Insurance Medical Research Fellowship.

2 Life Insurance Medical Research Fellow.

- Senior Fellow, National Institutes of Health. distilled water and evacuated with air after each period. Glomerular filtration rate was measured with mannitol in Cases 1 and 4, and with inulin in the remaining cases.4 Urea clearance was estimated manometrically (18), and phenolsulfonphthalein excretion by standard fractional collections (19).

\section{RESULTS}

The essential features are summarized in Table I. All five patients were males between the ages of 39 and 58. All had proven duodenal ulcers with pyloric obstruction. They were followed for periods of six to 17 months following the period of alkalosis and renal failure. In none was there any history of previous renal disease, and in only one was hypertension observed. All had suffered prolonged periods of vomiting, varying from weeks to months, prior to initial observations; this was associated in four with excessive intake of absorbable alkali. The biochemical changes characteristic of alkalosis were present initially in four of the five. It may be inferred that they were also present in the fifth (Case 4), since the first carbon dioxide content of the serum was measured two days after intensive administration of parenteral saline. The biochemical abnormalities and their relationship to the disturbed renal function are discussed at greater length in another report (16). All patients were relieved of the pyloric obstruction, four of them by operative intervention, and blood chemistry values returned to normal.

Serial measurements of glomerular filtration rate, effective renal plasma flow, and maximal tubular excretory capacity made in one patient from the time of the initial alkalosis and extending over a period of 17 months are shown in Figure 1. It is clear that all three functional measurements were about equally reduced. Although

\footnotetext{
4 We are indebted to Dr. W. P. Boger of Sharp and Dohme, Inc., for generous supplies of mannitol and sodium para-aminohippurate.
} 
CHARLES H. BURNETT, BELTON A. BURROWS, AND ROBERT R. COMMONS

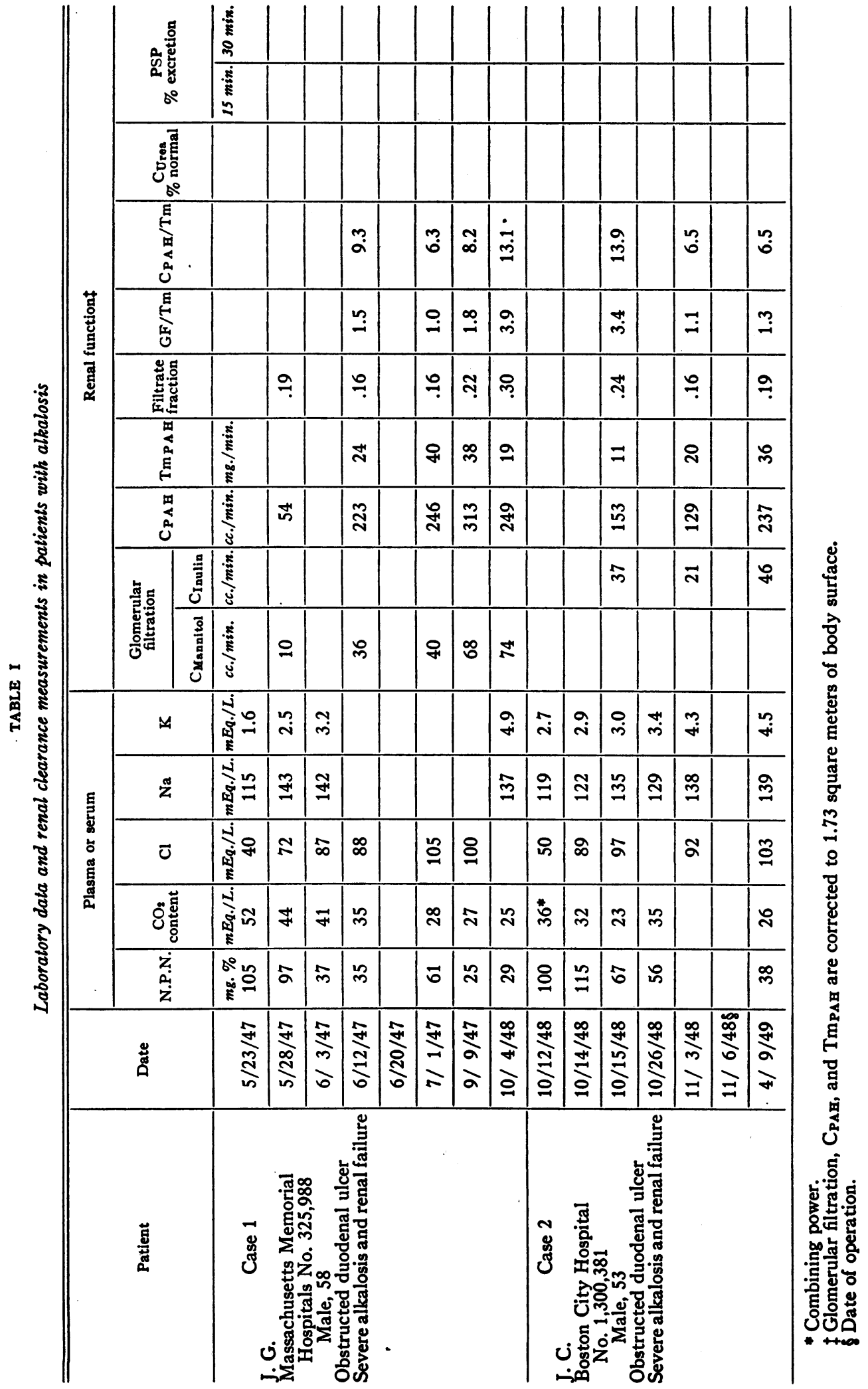


STUDIES OF ALKALOSIS. I.

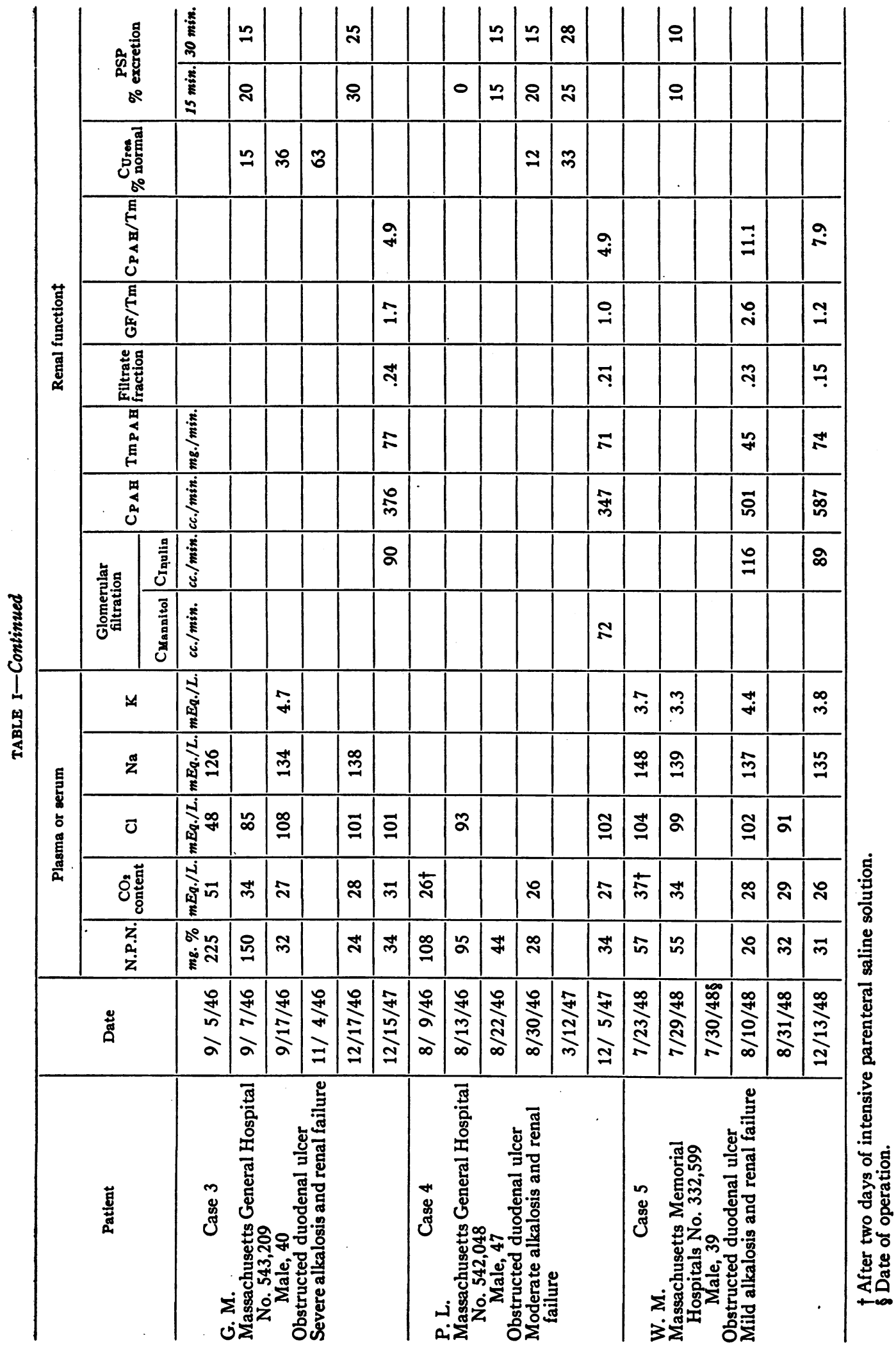



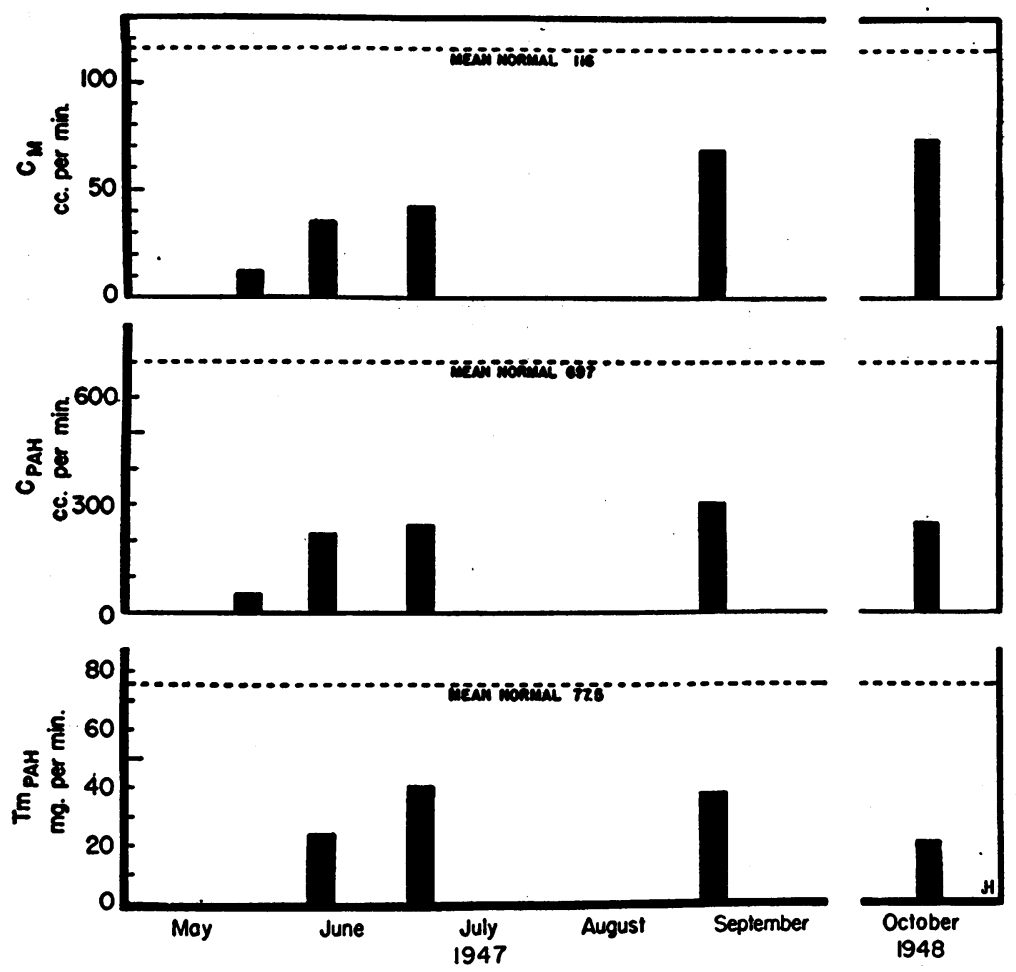

Fig. 1. Serial Renal Clearance Measurements in a Patient with Severe Alkalosis (Case 1)

renal function progressively improved it never returned to normal; indeed, the last measurements showed evidence of progressive impairment of tubular function, as suggested by the high filtration fraction and lower maximal tubular excretory capacity. In Case 2 , in which clearance studies were made three days after the most severe alkalosis, there was a similar general reduction in all measurements. Three weeks later the renal function remained greatly impaired. At this time the alkalosis had been relieved, but azotemia was still present. Six months later, although function was improved and blood chemistry determinations were normal, filtration rate, effective plasma flow, and maximal tubular excretory capacity were only 40 to 50 per cent of normal. Although these clearances were not done early in Cases 3 and 4, the azotemia, diminished urea clearance, and phenolsulfonphthalein excretions present during the acute episode established the existence of renal failure. Clearance measurements 15 and 16 months later, respectively, were similar in that in each, glomerular filtration rates and effective plasma flow were both low, while maximal tubular excretory ca- pacities were normal. Only the maximal tubular excretory capacity was low in Case 5 two weeks after relief of mild alkalosis and renal insufficiency. All clearances were essentially normal four months later, except for a slight drop in inulin clearance compared with the initial observation.

Examination of filtration fractions, GF/Tm and $\mathrm{C}_{\mathrm{PAH}} / \mathrm{Tm}$ ratios reveals no constant pattern either between serial measurements in individual patients or between the various patients. In spite of the absence of a characteristic functional defect, it is probably significant that in none of the five patients have all clearance measurements returned unequivocally to normal.

\section{DISCUSSION}

Evaluation of the relationship between alkalosis and renal impairment requires consideration of a number of factors. First, the initiating cause or causes of the acid-base abnormality is important, for alkalosis may result from either excessive intake of cations (especially sodium), from loss of anions in excess of cations, or from a com- 
bination of both factors. Second, the degree and reversibility of the renal insufficiency, if it does occur, should be determined. Third, the status of renal function prior to the alkalotic episode or episodes ideally should be known.

Whether excessive administration of alkali to individuals with normal renal function who have not been vomiting can permanently or even temporarily damage the kidneys is controversial (115). Many of the reports in the literature fail to state definitely whether the alkalosis and renal insufficiency were unassociated with vomiting or gastric aspirations. In Kirsner and Palmer's series where they clearly made this differentiation, excessive alkali in the absence of chloride loss through vomiting or aspiration of gastric contents did occasionally cause a fall in previously normal urea clearances if alkalosis occurred; but these returned to normal after the alkalosis was relieved (13). Acute alkalosis resulting from administration of large quantities of alkali caused temporary and inconstant changes in renal function in subjects with previously normal function (20). One patient showed a decrease in mannitol clearance from 130 to 84 after 10 days of intensive sodium bicarbonate administration, but no change in the effective plasma flow (21). In a recent series of six patients there was suggestive, but not positive, evidence that chronic renal failure may have resulted from prolonged excessive intake of alkali and milk (22). That kidneys already impaired either by chronic or acute renal insufficiency may have poor tolerance to alkali seems fairly well established (23-25).

As usually seen clinically, this syndrome occurs where there has been vomiting, although there may be an accompanying ingestion of alkali (115). Hence, there is depletion not only of chloride but also of water, sodium and potassium (16, 26). All of the patients here reported fell into this category. It is the authors' opinion that the profound changes which occur in water and electrolyte metabolism might partially explain the initial severely diminished renal function which was observed, and that this functional impairment is not unlike that occurring in lower nephron nephrosis (27-28). Changes in the inulin clearance similar to those reported here have been noted previously by $\mathrm{McCance}$ (10). But these patients differed from those with lower nephron nephrosis in that recovery was slower and less complete.

The essential features of the syndrome are that severe depression of renal function usually, if not invariably, occurs during alkalotic episodes regardless of whether previous renal insufficiency existed. Further, this depression of function is partially reversible, although it may require many months for improvement to take place. Whether the failure of patients in this series completely to re-establish normal renal function after more than a year was due to the alkalotic episode per se or simply reflected an insult to pre-existent renal disease cannot be stated positively. In none of them was there any known history of previous renal disease, although one was known to have had hypertension for five years.

\section{SUMMARY AND CONCLUSIONS}

1. Five male patients with pyloric obstruction and excessive vomiting due to duodenal ulcer were studied. Four of these gave a history of previous excessive ingestion of absorbable alkali.

2. In three patients severe alkalosis and in one patient mild alkalosis were demonstrated. An elevated carbon dioxide content of the serum was not actually demonstrated in one patient, but from the history it may be logically inferred that alkalosis had been present shortly before observation.

3. Four patients had severe renal failure during the acute alkalotic episodes. One patient had mild renal failure accompanying mild alkalosis.

4. Renal clearance measurements demonstrated : (a) marked reduction in glomerular filtration rate, effective plasma flow, and maximal tubular excretory capacity during the acute episodes; (b) marked but gradual improvement in function following the acute episodes; (c) failure of all patients followed for six to 17 months completely to regain normal renal function; $(d)$ absence of any definite functional pattern in this type of renal insufficiency.

5. The suggestion is made that the acute renal insufficiency occurring during alkalosis resembles in some respects lower nephron nephrosis. Whether permanent renal damage can result from this insult administered to previously normal kidneys is not evident from our data. 


\section{ACKNOWLEDGMENTS}

We are grateful to Dr. J. H. Means for permission to report patient G. M.; to Dr. Earle Chapman for patient P. L.; and to Constance Qua, Frances Scher, and Elizabeth Nolan for technical assistance.

\section{BIBLIOGRAPHY}

1. Hardt, L. L., and Rivers, A. B., Toxic manifestations following the alkaline treatment of peptic ulcer. Arch. Int. Med., 1923, 31, 171.

2. Brown, G. E., Eusterman, G. B., Hartman, H. R., and Rowntree, L. G., Toxic nephritis in pyloric and duodenal obstruction; renal insufficiency complicating gastric tetany. Arch. Int. Med., 1923, $32,425$.

3. Gatewood, W. E., Gaebler, O. H., Muntwyler, E., and Myers, V. C., Alkalosis in patients with peptic ulcer. Arch. Int. Med., 1928, 42, 79.

4. Cooke, A. M., Alkalosis occurring in the alkaline treatment of peptic ulcers. Quart. J. Med., 1932, $1,527$.

5. Cope, C. L., Base changes in alkalosis produced by treatment of gastric ulcer with alkalies. Clin. Sc. 1936, 2, 287.

6. Oakley, W., Alkalosis arising in treatment of peptic ulcer. Lancet, 1935, 2, 187.

7. Berger, E. H., and Binger, M. W., Status of the kidneys in alkalosis. J. A. M. A., 1935, 104, 1383.

8. Steele, J. M., Renal insufficiency developing during prolonged use of alkalis; report of case. J. A. M. A., 1936, 106, 2049.

9. Jeghers, H., and Lerner, H. H., Syndrome of alkalosis complicating treatment of peptic ulcer; report of cases with review of pathogenesis, clinical aspects and treatment. New England J. Med., 1936, 214, 1236

10. McCance, R. A., and Widdowson, E. M., Alkalosis with disordered kidney functions; observations on case. Lancet, 1937, 2, 247.

11. Eisele, C. W., Changes in the acid-base balance during alkali treatment for peptic ulcer; clinical analysis of alkalosis in 28 patients. Arch. Int. Med., 1939, 63, 1048.

12. Nicol, B. M., The renal changes in alkalosis. Quart. J. Med., 1940, 9, 91.

13. Kirsner, J. B., and Palmer, W. L., Alkalosis complicating the Sippy treatment of peptic ulcer; analysis of 135 episodes. Arch. Int. Med., 1942, 69, 789.
14. Sanderson, P. H., Renal failure following abdominal catastrophe and alkalosis. Clin. Sc., 1948, 6, 207.

15. Grace, W. J., and Barr, D. P., Complications of alkalosis. Am. J. Med., 1948, 4, 331.

16. Burnett, C. H., Burrows, B. A., Commons, R. R., and Towery, B. T., Studies of alkalosis. II. Electrolyte abnormalities in alkalosis resulting from pyloric obstruction. J. Clin. Invest., 1950, 29, 175.

17. Goldring, W., and Chasis, H., Hypertension and Hypertensive Disease. The Commonwealth Fund, New York, 1944.

18. Peters, J. P., and Van Slyke, D. D., Quantitative Clinical Chemistry. Vol. II. Methods. The Williams \& Wilkins Company, Baltimore, Maryland, 1932.

19. Chapman, E. M., and Halsted, J. A., Fractional phenolsulphonephthalein test in Bright's disease. Am. J. M. Sc., 1933, 186, 223.

20. Army Malaria Research Unit, Oxford, Effect of large doses of alkali on kidney function. Lancet, 1945, 2, 701.

21. Burnett, C. H., and Burrows, B. A. Unpublished observations.

22. Burnett, C. H., Commons, R. R., Albright, F., and Howard, J. E., Hypercalcemia without hypercalcuria or hypophosphatemia, calcinosis and renal insufficiency. New England J. Med., 1949, 240, 787.

23. Palmer, W. W., Alkali retention and reserve. J. Biol. Chem., 1917, 32, 499.

24. Ellis, A. W. M., Disturbance of acid-base equilibrium of blood to alkaline side: alkalaemia. Quart. J. Med., 1924, 17, 405.

25. Burnett, C. H., Shapiro, S. L., Simeone, F. A., Beecher, H. K., Mallory, T. B., and Sullivan, E. R., Effects and use of alkalies in traumatic shock. Surgery, 1947, 22, 1029.

26. Gamble, J. L., and Ross, S. G., The factors in the dehydration following pyloric obstruction. J. Clin. Invest., 1925, 1, 403.

27. Burnett, C. H., Shapiro, S. L., Simeone, F. A., Beecher, H. K., Mallory, T. B., and Sullivan, E. R., Post-traumatic renal insufficiency. Surgery, 1947, 22, 994.

28. Burnett, C. H., Shapiro, S. L., Simeone, F. A., Beecher, H. K., Mallory, T. B., and Sullivan, E. R., Renal function studies in the wounded. Surgery, 1947, 22, 856. 